Article

\title{
Are More Intelligent People Happier? Emotional Intelligence as Mediator between Need for Relatedness, Happiness and Flourishing
}

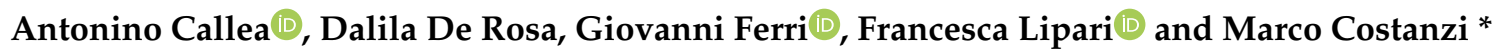 \\ Department of Human Sciences, LUMSA University, 00193 Rome, Italy; a.callea@lumsa.it (A.C.); \\ dal.derosa@gmail.com (D.D.R.); g.ferri@lumsa.it (G.F.); f.lipari1@lumsa.it (F.L.) \\ * Correspondence: m.costanzi@lumsa.it; Tel.: +39-06-68422284
}

Received: 29 December 2018; Accepted: 13 February 2019; Published: 16 February 2019

check for updates

\begin{abstract}
The psychology of sustainability and sustainable development aims to study the personal characteristics that promote effective and sustainable well-being for individuals and environments from a psychological research perspective. According to the self-determination theory, the psychological need for relatedness is positively associated with happiness and flourishing. In turn, emotional intelligence, i.e., understanding and managing one's own emotions and recognizing others' emotions, may play a key role in this association. Therefore, the present study investigates the mediating role of emotional intelligence in the relationship between need for relatedness and both happiness and flourishing. Basic Psychological Needs scales (BPNs), Emotional Intelligence Scale (EIS), Flourishing Scale, and Happiness Scale were administered to 216 Italian participants (age range 15-66 years old). A mediation model via a structural equation model for path analysis was tested. The results showed that the psychological need for relatedness positively associated with both happiness and flourishing and that emotional intelligence mediated these associations. These results suggest that important interventions may be performed to promote flourishing and happiness, enhancing emotional intelligence through specific training differently from need for relatedness that, instead, can be considered substantially stable.
\end{abstract}

Keywords: positive psychology; emotional intelligence; need for relatedness; happiness; flourishing

\section{Introduction}

In a world where consumption of natural resources is on the rise [1], it is important to identify psychological characteristics that promote positive behaviors towards environment sustainability and individual well-being. Several studies concur that both positive psychological antecedents (e.g., virtues, emotions, etc.) and consequences (e.g., well-being, happiness, etc.) are significant determinants of pro-social, as well as pro-environmental behaviors [2]. Interestingly, a correlation between sustainable behavior and happiness has been postulated, i.e., happier people behave in a more sustainable manner and sustainable behaviors increase happy feelings in people [3], suggesting that seeking happiness might have clear implications for both sustainability and personal well-being. According to Seligman's view, 'authentic' happiness or well-being requires five elements: Positive emotions, engagement, relationships, meaning, and accomplishment [4]. Thus, the concept of personal well-being has to be considered as a combination of both hedonic (i.e., feeling good) and eudaimonic components (i.e., functioning well) [5]. Indeed, Huppert and colleagues [5] proposed a broader definition of personal well-being that extends to the concept of flourishing (i.e., the experience of life going well) and encompasses three factors: Positive characteristics (emotional stability, vitality, optimism, resilience, and self-esteem), positive functioning (engagement, competence, meaning, and positive relationships), and positive appraisal (life satisfaction and positive emotion) $[5,6]$. 
Although both hedonic and eudaimonic factors are crucial for the pursuit of 'authentic' happiness, distinctions between them deserve to be considered. While the former basically relates to the affective level, eudaimonic well-being seems to be related to the feeling of competence, pride, etc. At a functioning level, hedonia is linked to the sense of pleasure, while eudaimonia is linked to meaning, value, personal growth, etc. [7,8]. From a biological point of view, hedonia is related to the hotspot activity of meso-cortico-limbic structures, while eudaimonic aspects mainly involve the activity of the neocortical default network $[9,10]$. Furthermore, hedonia is associated with immediate well-being, while eudaimonia is associated with long-term well-being. Interesting differences emerge when social aspects of well-being are considered. Indeed, when compared to the pursuit of hedonia, eudaimonic well-being seems to be reached when others' well-being is fostered, suggesting that eudaimonia is more related to the well-being of the surrounding social world [11]. Individuals who belong to a social network and who feel satisfied from relationships with others generally display a better quality of life [12,13]. In particular, empirical evidence shows that involvement in social activity significantly increases happiness and life satisfaction [14-18]. Moreover, when the eudaimonic side is considered, the social relation dimension appears to be a crucial requirement for flourishing [19].

This theoretical approach has also been extended to entrepreneurship research, in which concepts belonging to positive psychology are incorporated into business ideas named "sustainability-as-flourishing" and "mirror flourishing", with the former describing the possibility that both humans and other living beings can flourish together on Earth, and the latter describing reflexive flourishing, in which good things happen to good people [20,21].

Thus, assessing factors that influence both flourishing and happiness is important, not only for decision-makers in organizations, but also for the general public too [6]. Indeed, an increased interest among citizens in government policies aimed at improving subjective wellbeing has been revealed [22].

The above reported results strongly suggest that the social aspects of eudaimonic well-being could be crucial for sustainability. However, although social concepts are well incorporated into models for sustainable development-encompassing both environmental and normative points of view (e.g., social sustainability) [23]—the "psychological dimension" needs to be further investigated. Indeed, the necessity to increase relationships among individuals has been recently proposed in a new multi-centric perspective aimed at improving sustainable development [24].

The Self-Determination Theory (SDT) [25] offers an interesting theoretical frame to investigate psychological needs, as well as people's inherent growth tendencies, which orient self-motivation towards the promotion of subjective well-being. According to the SDT, three innate motivational factors seem to be essential for living well: (i) Autonomy, which refers to the experience of behaving in accordance with one's own interests or values [26]; (ii) competence, which regards the sense of mastery $[27,28]$; (iii) relatedness, which regards the sense of belongingness and, more in general, refers to the propensity to be connected with others [29-32]. Satisfying these universal innate psychological needs is essential for well-being [33], happiness [34] and for optimal functioning [35]. While both autonomy and competence are widely recognized to be essential for happiness and well-being [36-38], the specific role of relatedness in happiness and flourishing has not been fully understood.

Demir and Ozdemir [39] found that the relationship between close social context (namely, the closest friendship) and happiness is mediated by the satisfaction of psychological needs [39]. Interestingly, the need for relatedness mediates the relationship between involvement in enjoyable social activities and emotional well-being [33] and emerges as the SDT factor to be mainly involved in the development of prosocial tendency [40].

Thus, although a relationship between the need for relatedness and happiness could be envisaged, other intrinsic factors may enter this association. For instance, emotional intelligence mediates the relationship between general self-determination and psychological well-being [41]. In particular, a mediation role for emotional intelligence in the relationship between personal traits and positive resources like optimism and hope-which are predictors of subjective well-being — has recently been observed [42]. 
Emotional intelligence is defined as "the ability to perceive and express emotion, assimilate emotion in thought, understand and reason with emotion, and regulate emotion in the self and in others" [43]. Several studies have revealed the main role of emotional intelligence in determining individual happiness and flourishing [44], as well as the promotion of prosocial behaviors and sustainability $[45,46]$. A significant correlation between the need for relatedness and both emotional perception and regulation has also been observed [47]. Interestingly, among the three psychological needs included in the SDT, only relatedness accounts for majority of the variance in emotional traits strongly related to subjective well-being $[48,49]$. Therefore, considering the possible relationship between need for relatedness and subjective well-being (e.g., happiness and flourishing), a mediation role for emotional intelligence is conceivable and deserves to be investigated.

\section{Aim and Hypotheses}

Considering the theoretical framework herein described, the main aim of the present study is to investigate the possible role of emotional intelligence in mediating the relationship between need for relatedness and both happiness and flourishing.

Consequently, the following hypotheses can be formulated:

Hypothesis 1 (H1). Need for relatedness will be positively and significantly related to emotional intelligence.

Hypothesis 2 (H2). Emotional intelligence will be positively related to flourishing (H2a) and happiness $(\mathrm{H} 2 b)$.

Hypothesis 3 (H3). The relationship between need for relatedness and both flourishing (H3a) and happiness (H3b) will be mediated by emotional intelligence.

\section{Materials and Methods}

\subsection{Participants}

The participants were 216 Italian adults, $16.2 \%$ male and $83.8 \%$ female. On an average, the participants were 33.92 years old $(\mathrm{SD}=12.02)$, ranging from 18 to 66 . The majority of participants were single $(64.8 \%), 30.6 \%$ married or cohabiting, $3.8 \%$ separated or divorced, and $0.9 \%$ widowed.

With regard to education, $58.9 \%$ had a university degree, $34.7 \%$ had a high school degree, and the remaining had only completed compulsory education. The majority of participants $(55.1 \%)$ were employed, $19.9 \%$ were students, $7.9 \%$ were employed students, $6.9 \%$ were unemployed and $0.9 \%$ were retired.

\subsection{Measures}

The need for relatedness satisfaction was assessed with three items of the Basic Psychological Needs Satisfaction scales (BPNSs), proposed by Deci and Ryan [25], with a scale ranging from 1 (not at all true) to 7 (very true). The Italian version of the BPNSs [50] shows an adequate level of reliability, and convergent and discriminant validity. In fact, the results of the hierarchical three-factor model, through CFA, reached good fit indices. Furthermore, Cronbach's $(\alpha \mathrm{s})$ reliability showed satisfactory results ( $\alpha=0.82$ for autonomy, $\alpha=0.79$ for relatedness satisfaction and $\alpha=0.88$ for competence). Specifically, the relatedness subscale measures the degree to which people feel satisfied by their personal relationships. An example item is, "People in my life care about me". High scores indicate a high level of satisfaction with regard to the need for relatedness.

Emotional intelligence was assessed with the Emotional Intelligence Scale (EIS), proposed by Shutte and colleagues [51], using the Italian version by Di Fabio, Giannini and Palazzeschi [52]. It was composed of 33 items, with a Likert scale ranging from 1 (strongly disagree) to 5 (completely agree). The Italian validation proposed a factor solution in three dimensions: "Evaluation and Expression of 
Emotions" $(\alpha=0.84)$, "Adjustment of Emotions" $(\alpha=0.82)$, and "Using Emotions in Problem Solving" $(\alpha=0.79)$. An example is: "I can understand how others feel by listening to the tone of their voice." Some authors [51,53] suggest that this scale also be used as unidimensional to provide a global measure of emotional intelligence. High scores indicate a high level of emotional intelligence.

Flourishing was assessed with nine items of the European Social Survey [54], with a Likert scale ranging from 1 (strongly disagree) to 5 (completely agree). According to Huppert and So's definition [55], flourishing is referred as the opposite of mental disorder, rather than its mere absence. The positive features of flourishing concern competence, emotional stability, engagement, meaning, optimism, positive relationships, resilience, self-esteem and vitality. An example is: "I am always optimistic about my future." High scores indicate a high level of flourishing.

Happiness was measured with a single item through the positive emotion factor of the European Social Survey [54]. The item was: "Taking all things together, how happy would you say you are?", rated on a scale ranging from 0 (extremely unhappy) to 10 (extremely happy).

\subsection{Procedure and Data Analysis}

The participants were selected via a snowball procedure, beginning with people known to the researchers. The questionnaires were collected via Computer Assisted Web Interviewing (CAWI) through an online platform. After completing the questionnaire, each participant was asked to send the link to other people. The survey was designed to respect privacy and anonymity, ensuring that personal data is treated in accordance with Italian privacy law (Law Decree DL-196/2003) and analyzed in an aggregated manner. As a matter of fact, informed consent was requested of the participants. The workers voluntarily and freely authorized the use of anonymous/collective data.

Pearson correlations was performed in order to explore the relationships among variables. Measurement model and mediation hypotheses were tested through a structural equation model [56,57], by using the software M-PLUS 7.3. For reasons of parsimony and as suggested by previous and recent literature $[58,59]$, we applied the item parcelling technique to the two variables with the highest number of items (i.e., emotional intelligence and flourishing). For analyses with a structural equation model, the procedures reported by Little and Collaborators [60] were followed. Therefore, the model consisted of three items for need for relatedness, three parcels for emotional intelligence, three parcels for flourishing, and a single item for happiness. The method of estimation was Robust Maximum Likelihood (Robust ML); the covariances among the latent variables were set. The adjustment of the model was assessed with $\chi^{2}$ and the following fit indices: comparative fit (CFI) and non-normed fit (NNFI) indexes (values $\geq 0.95$ indicate a very good fit); root mean squared error of approximation (RMSEA) and standardized root mean square residual (SRMR; values $\leq 0.05$ indicate a very good fit). Finally, in order to test the statistical significance of direct, indirect and total effects, a bootstrapping procedure was used, employing 5000 samples with replacement from the full sample to construct bias-corrected 95 percent Confidence Intervals (CI) [61]. An effect is significant when zero is not included in the CI [61].

\section{Results}

\subsection{Preliminary Analysis: Comparing Scores for Socio-Demographic Characteristics}

The scores relative to the investigated variables were compared considering the main socio-demographic characteristics: gender, age, level of education, marital status and occupational status. In regards to the gender, there were no significant differences between males and females in respect to need for relatedness, emotional intelligence and happiness. Males $(M=3.81 ; S D=0.59)$ had a higher level of flourishing than females $(M=3.56 ; S D=0.67), t(214)=2.02 ; p<0.05$. Age was significantly and positively correlated to need for relatedness $(r=0.16)$, emotional intelligence $(r=0.15)$, flourishing $(r=0.17)$ and happiness $(r=0.16)$. With respect to the level of education, there were no significant differences across university degree, high-school degree, and compulsory education when 
the investigated variables were considered. Moreover, no significant differences were found in marital status (i.e., among single, married or cohabiting, separated or divorced and widowed). With respect to occupational status, there were no significant differences for relatedness and emotional intelligence, while unemployed had a lower level of flourishing, $\mathrm{F}(4 ; 211)=3.16, p<0.05$, and happiness, $\mathrm{F}(4 ; 211)$ $=3.16, p<0.05$, in comparisons to other groups (employed, students, employed students and retired).

\subsection{Measurement Model}

In order to examine the potential effects of the common method bias, we compared three different models: (M1) the hypothesized four-factor model (i.e., need for relatedness, emotional intelligence, flourishing, happiness), (M2) a model in which all items loaded on a single factor, and (M3) a model in which the items loaded both on their expected factor and on a latent common method factor $[62,63]$. Furthermore, the hypothesized measurement model (M1) was also compared to the following models: three-factor model where both flourishing and happiness (criteria) were combined in a single factor, while need for relatedness and emotional intelligence were measured as independent factors (M4); two-factor model where flourishing and happiness (criteria) were combined in a single factor, as well as need for relatedness and emotional intelligence (predictors) (M5). The models were compared by the fit indices described above. The hypothesized measurement model and other alternative models are shown in Table 1. The results showed that the hypothesized measurement model was the best fit for the data, with alternative measurement constructs resulting in a poorer fit $(<0.001)$ [64].

Table 1. Results of measurement model.

\begin{tabular}{ccccccccc}
\hline Model & $\boldsymbol{\chi}^{\mathbf{2}}$ & $\mathbf{d f}$ & CFI & RMSEA & SRMR & $\boldsymbol{\Delta} \boldsymbol{\chi}^{\mathbf{2}}$ & $\boldsymbol{\Delta d f}$ & $\boldsymbol{p}$ \\
\hline Model 1 & 70.91 & 31 & 0.943 & 0.095 & 0.045 & - & - & - \\
Model 2 & 187.91 & 35 & 0.839 & 0.142 & 0.077 & 117.00 & 4 & $<0.001$ \\
Model 3 & 127.01 & 35 & 0.900 & 0.117 & 0.063 & 57.90 & 4 & $<0.001$ \\
Model 4 & 116.94 & 32 & 0.911 & 0.111 & 0.056 & 46.03 & 1 & $<0.001$ \\
Model 5 & 145.33 & 34 & 0.881 & 0.123 & 0.064 & 74.42 & 3 & $<0.001$ \\
\hline
\end{tabular}

In order to further test the possible overlap of observed and latent variables at the measurement level, we evaluated convergent and discriminant validity following a procedure developed by Fornell and Larcker [65]. For convergent validity, we measured Average Variance Extracted (AVE), i.e., the level of variance captured by a latent variable versus the level due to measurement error of its indicator. AVE values are included between 0 and 1 ; they are considered acceptable when higher than 0.50 , demonstrating that more than $50 \%$ of the variance of the latent variable is due to its indicators. For discriminant validity, we used a comparison between the AVE of each latent variable with the Maximum Shared Variance (MSV) between latent variables. Specifically, MSV is the square of the correlation coefficient between each couple of latent variables. It derives that if AVE of each construct is higher than its MSV with any other construct, discriminant validity was supported. The results of AVE, MSV and correlations among latent variables are reported in Table 2. The results showed that the AVE values ranged from 0.56 (need for relatedness) to 0.70 (flourishing). Furthermore, the AVE of each construct was higher than its MSV. 
Table 2. Correlations among variables and Cronbach's $\alpha \mathrm{s}$, AVE and MSV.

\begin{tabular}{ccccccc}
\hline & $\begin{array}{c}\text { Need for } \\
\text { Relatedness }\end{array}$ & $\begin{array}{c}\text { Emotional } \\
\text { Intelligence }\end{array}$ & Flourishing & Happiness & AVE & MSV \\
\hline Need for relatedness & $(0.71)$ & $0.72^{* *}$ & $0.67^{* *}$ & $0.34^{* *}$ & 0.56 & 0.52 \\
Emotional intelligence & $0.59^{* *}$ & $(0.88)$ & $0.81^{* *}$ & $0.43^{* *}$ & 0.68 & 0.66 \\
Flourishing & $0.51^{* *}$ & $0.69^{* *}$ & $(0.83)$ & $0.69^{* *}$ & 0.70 & 0.66 \\
Happiness & $0.31^{* *}$ & $0.35^{* *}$ & $0.66^{* *}$ & - & - & - \\
$M$ & 3.85 & 3.80 & 3.61 & 7.13 & - & - \\
$S D$ & 0.69 & 0.49 & 0.66 & 1.60 & - & - \\
\hline
\end{tabular}

Note. $N=216 .{ }^{* *} p<0.01$. Cronbach's $\alpha$ s are in parentheses. Correlation among latent variables in M1 is shown above the diagonal, while correlation among scores of the scales is shown below the diagonal. AVE: average variance extracted; MSV: Maximum Shared Variance.

Considering the fit showed by the four-factor measurement model, the results obtained with the analysis of convergent and discriminant validity suggest that the hypothesized model is adequate. Therefore, the common method variance and overlap among items for the measurement model should not be a major issue.

With respect to the correlation results (Table 2), the need for relatedness was positively correlated to emotional intelligence, flourishing, and happiness. Furthermore, emotional intelligence was also positively correlated to happiness and flourishing. Finally, happiness and flourishing were positively and significantly correlated. The results were substantially similar, in terms of significance and sign, whether correlation among latent variables or correlation among scores of the scales was considered.

\subsection{Mediation Model}

The hypothesized model (Figure 1) aimed to test the mediating role of emotional intelligence in the relationship between need for relatedness and outcomes (i.e., flourishing and happiness).

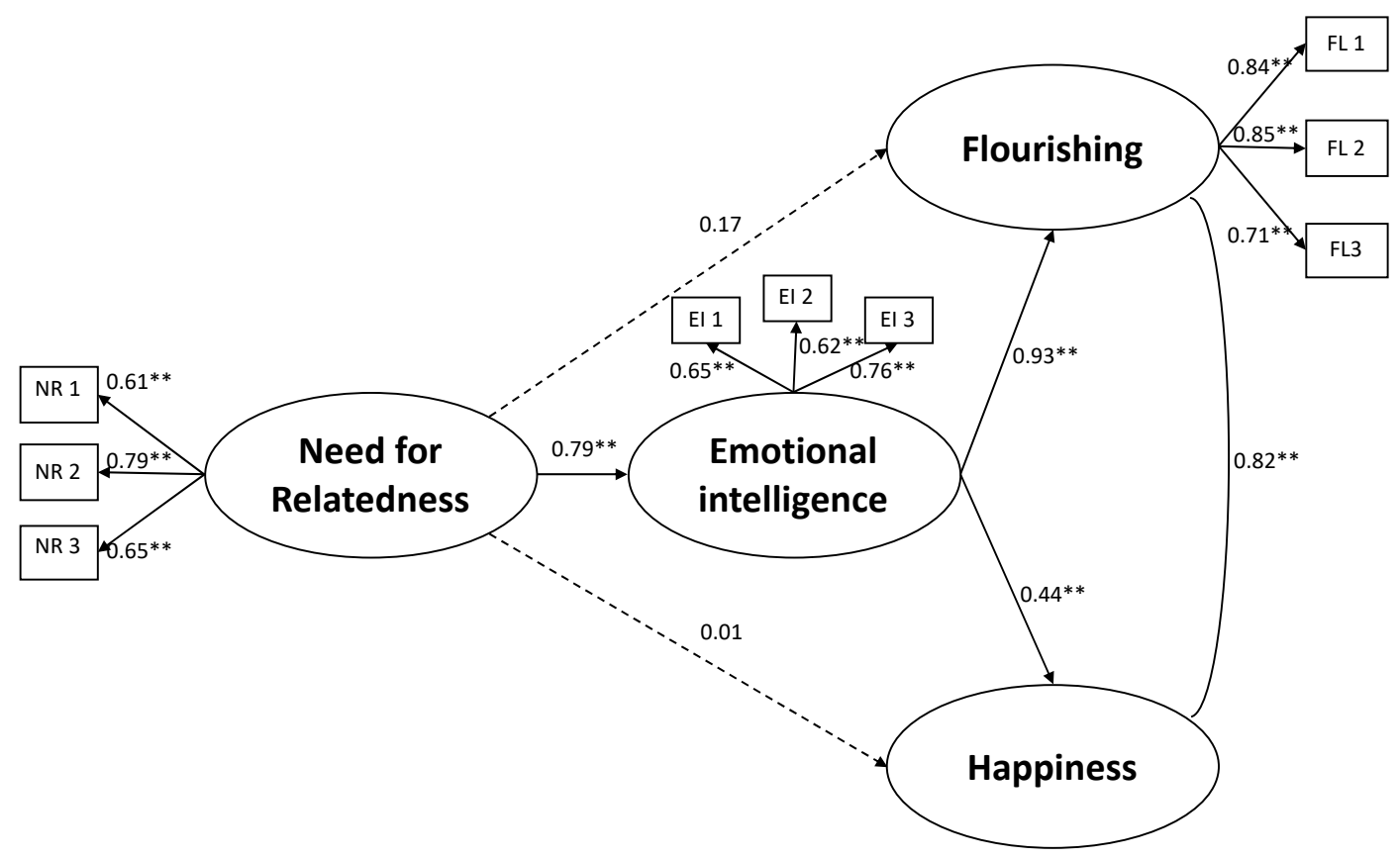

Figure 1. Mediation model of Emotional intelligence in the relationship between Need for Relatedness and both Flourishing and Happiness with standardized path coefficients. Discontinuous lines mean non-significant relationships. Note. ${ }^{*} p<0.05 ;{ }^{* *} p<0.01$.

The mediation model showed a good adjusted model $(\chi(\mathrm{df})=99.97(32), p<0.001$; RMSEA $=$ 0.099; $\mathrm{SRMR}=0.052 ; \mathrm{CFI}=0.929 ; \mathrm{NNFI}=0.900)$. First, the results showed that the need for relatedness 
was positively and significantly linked to emotional intelligence $(\beta=0.79, p<0.001)$, supporting $H 1$. Furthermore, emotional intelligence was positively and significantly related to flourishing ( $\beta=0.93$, $p<0.001)$ and happiness $(\beta=0.44, p<0.001)$, supporting $H 2 a$ and $H 2 b$.

With respect to the mediation hypotheses, the total effect of the need for relatedness on flourishing was significant and positive (0.171, with bootstrap CI between 0.203 and 0.545$)$. The direct effect was not statistically significant $(0.167$, with bootstrap CI between 0.064 and 0.271$)$. The indirect effect of the need for relatedness on flourishing via emotional intelligence was significant and positive $(0.488$, with bootstrap CI between 0.376 and 0.600 ), showing that emotional intelligence totally mediated (explaining $74 \%$ of the total variance) the relationship between the need for relatedness and flourishing, supporting $H 3 a$.

Furthermore, the total effect of the need for relatedness on happiness was significant and positive (0.338, with bootstrap CI between 0.198 and 0.478 ). The direct effect was not statistically significant (0.009, with bootstrap CI between 0.524 and 0.542$)$. The indirect effect of the need for relatedness on happiness via emotional intelligence was significant and positive $(0.329$, with bootstrap CI between 0.160 and 0.498 ), showing that emotional intelligence partially mediated (explaining $97 \%$ of the total variance) the relationship between the need for relatedness and happiness, supporting H3b. The statistical significance of the standardized direct, indirect and total effects (and their relative bootstrap CI 95\%) is reported in Table 3.

Table 3. Results of mediation with standardized effect and 95\% bootstrap CI.

\begin{tabular}{ccc}
\hline Effect & $\begin{array}{c}\text { Flourishing } \\
\text { Effect }[\boldsymbol{L L} ; \boldsymbol{U L}]\end{array}$ & $\begin{array}{c}\text { Happiness } \\
\text { Effect }[\boldsymbol{L} \boldsymbol{L} ; \boldsymbol{U L}]\end{array}$ \\
\hline Total effect & $0.659[0.546 ; 0.772]$ & $0.338[0.198 ; 0.478]$ \\
Indirect effect & $0.349[0.261 ; 0.438]$ & $0.329[0.160 ; 0.4 .98]$ \\
Direct effect & $0.171[-0.203 ; 0.545]$ & $0.009[-0.524 ; 0.506]$ \\
\hline \multicolumn{2}{c}{ Note. CI = Confidence Interval; LL = Lower Level; UL = Upper Level. }
\end{tabular}

\subsection{Test of the Alternative Model}

We also tested the alternative model in which the need for relatedness mediates between the emotional intelligence and outcomes. The alternative model showed generally unsatisfactory fit indices $(\chi(32)=129.35, p<0.01 ; \mathrm{RMSEA}=0.119 ; \mathrm{SRMR}=0.006 ; \mathrm{CFI}=0.798 ; \mathrm{NNFI}=0.756)$. Moreover, the AIC of the alternative model was 1434.00 while the AIC of the proposed model was 4349.97, providing additional empirical support for the hypothesized mediating role of emotional intelligence in the relationship between the need for relatedness and outcomes.

\section{Discussion}

In the present study, we investigated the mediating role of emotional intelligence in the relationship between need for relatedness and individual well-being (i.e., flourishing and happiness).

In particular, our results supported Hypothesis 1, stating that the need for relatedness would positively relate to emotional intelligence. According to the SDT, psychological needs contain both cognitive and affective components and the need for relatedness appears as an important motivation factor for the development of emotional intelligence [25]. Moreover, it has been observed that the capability in managing with emotions is associated with the emotion-intrinsic motivation relationship [66]. More recently, Watson and Kleinert [67] showed that coaches' emotional intelligence is related to basic need satisfaction in athletes. Despite these pieces of evidence, the explicit role of emotions in the motivation-generative mechanism remains poorly investigated. The results we obtained strongly support the relationship between basic psychological needs and emotional intelligence, indicating that people with higher need for relatedness will tend to develop a better emotional intelligence. 
Hypothesis 2 stated that emotional intelligence would be positively related to flourishing and happiness. Our results indicated that people with higher levels of emotional intelligence showed higher levels of flourishing and happiness, supporting Hypothesis 2. This positive nexus is in line with previous studies detecting a positive contribution of emotional intelligence on promoting pro-social behaviour and sustainability [45,46], as well as on individual well-being [68].

Finally, our results also seemed to confirm Hypothesis 3, which stated that the contribution of the need for relatedness to flourishing and happiness would be mediated by emotional intelligence. Indeed, the need for relatedness contributed to individual well-being through both a direct pathway and an indirect route, which involves emotional intelligence. People who showed higher levels of need for relatedness were not only more flourished and happier, but also more emotionally intelligent. In turn, being more emotionally intelligent did increase the levels of both flourishing and happiness.

Recent results indicated that emotional intelligence mediates the relationship between personality traits and both hope and optimism, suggesting that stable factors and positive outcomes might be modulated through the mediation role of emotional intelligence [42]. The role of individual differences on the strength of implicit motives in the relationship between needs for relatedness and well-being has also been observed [69].

To the best of our knowledge, here we show for the first time the specific mediating role of emotional intelligence in the relationship between basic psychological needs and personal well-being, measured as flourishing and happiness.

Since, pro-social and pro-environmental behaviours are necessary factors for sustainability, and both of these factors seem to be determined by positive psychological antecedents (e.g., emotion) and consequences (e.g., happiness) [70-72], we may speculate that acting on emotional intelligence could be a plausible intervention towards promoting sustainable behaviours.

Some limitations in the present study have to be considered, which are worthy to address in future research. Firstly, the snowball procedure, i.e., no probabilistic sampling, limited the generalizability of our results. On the other hand, the snowball procedure allowed us to reach a high sample heterogeneity in terms of socio-demographic characteristics [73]. However, we tested mediation hypothesis by using the bootstrapping method, which allow us to partially overcome shortcomings that may have undermined the generalizability [74]. Future studies need to focus on this limit by considering a bigger and more representative sample. Secondly, the cross-sectional nature of our study prevents us from drawing causal conclusions. Nevertheless, the hypothesized model appears to empirically outperform an alternative model, in which the mediator is need for relatedness. Although longitudinal studies will be necessary to adequately test the proposed model in terms of modelling approach, at the present time, our model describes the data significantly better than its possible alternative. Clearly, further studies should replicate our results in order to fully disentangle reciprocal causal relations. Thirdly, all variables were measured through the same questionnaire, so common method variance could have altered our results. Moreover, possible overlaps among items measuring positive psychological constructs can be envisaged. Therefore, we preliminarily compared different measurement models and tested possible overlap among items by the analysis of convergent and discriminant validity. The results indicate that the hypothesized four constructs were sufficiently and empirically distinct. Thus, we believe that the present findings could hardly have been impaired by common method variance or measurement bias [63,75]. Fourthly, several socio-demographic (e.g., age, gender, level of education, marital status and occupational status) and socio-psychological (e.g., job satisfaction, self-evaluation, personality traits, etc.) factors can influence happiness and flourishing. Our results on socio-demographic factors indicate that flourishing and happiness does not depend on the level of education or marital status. On the other hand, both flourishing and happiness increase with the age. Furthermore, males show a higher level of flourishing than females, while unemployed displays a lower level of flourishing and happiness in comparisons to other groups. Further studies should be planned in order to increase the level of generalizability by considering the above reported factors. 
In sum, the present study paves the way for future research on the importance of emotional intelligence as a mediator in the relationship between personal needs and individual and social well-being in the perspective of the psychology of sustainability and sustainable development.

\section{Conclusions}

In conclusion, the results of our study seem to indicate that the significant part of the effect of need for relatedness on individual well-being is mediated by emotional intelligence. Thus, it is possible to envisage that the most emotionally intelligent people who are satisfied in the need for relatedness display higher levels of individual well-being. In supporting this view, the mediation role of emotional intelligence in the relationship between personal traits and positive resources predicting individual well-being has recently been observed [42]. Moreover, the finding that emotional intelligence is related to the need for relatedness factor of SDT adds new light on the relationship between motivational systems and emotional intelligence [66,67].

There is evidence suggesting that social aspects of eudaimonic well-being are crucial for sustainability $[23,24]$. In the light of our results, we can speculate that emotional intelligence is capable of increasing the individual and, consequently, social features needed for sustainable development. Indeed, previous studies have shown that emotional intelligence is positively related to social collaboration [76] and sustainability [77].

Therefore, although many factors can influence the relationship between the need for relatedness and individual well-being, the present study may indicate the possibility to intervene in emotional intelligence to increase individual well-being in order to face the challenges of the present global society.

Author Contributions: Conceptualization, M.C. and G.F.; methodology, A.C., D.D.R., F.L., M.C., G.F.; formal analysis and data curation, A.C.; investigation, A.C., D.D.R., F.L.; writing-original draft preparation, M.C., A.C.; project administration, M.C., G.F., funding acquisition, M.C.

Funding: This research was funded by LUMSA (Fondo per la ricerca 2016).

Conflicts of Interest: The authors declare no conflict of interest.

\section{References}

1. Meyfroidt, P.; Lambin, E.F.; Erb, K.-H.; Hertel, T.W. Globalization of land use: Distant drivers of land change and geographic displacement of land use. Curr. Opin. Environ. Sustain. 2013, 5, 438-444. [CrossRef]

2. Corral Verdugo, V. The positive psychology of sustainability. Environ. Dev. Sustain. 2012, 14, 651-666. [CrossRef]

3. Corral Verdugo, V.; Mireles-Acosta, J.; Tapia-Fonllem, C.; Fraijo-Sing, B. Happiness as correlate of sustainable behavior: A study of pro-ecological, frugal, equitable and altruistic actions that promote subjective wellbeing. Hum. Ecol. Rev. 2011, 18, 95-104.

4. Seligman, M. Flourish. A Visionary New Understanding of Happiness and Well-Being; Atria Books: New York, NY, USA, 2011; ISBN 9781439190753.

5. Huppert, F.A.; So, T.C. Flourishing Across Europe: Application of a new conceptual framework for defining well-being. Soc. Indic. Res. 2013, 110, 837-861. [CrossRef]

6. Hone, L.C.; Jarden, A.; Schofield, G.M.; Duncan, S. Measuring flourishing: The impact of operational definitions on the prevalence of high levels of wellbeing. Int. J. Wellbeing 2014, 4, 62-90. [CrossRef]

7. Huta, V.; Waterman, A.S. Eudaimonia and its distinction from hedonia: Developing a classification and terminology for understanding conceptual and operational definitions. J. Happiness Stud. 2014, 15, 1425-1456. [CrossRef]

8. Huta, V. An overview of hedonic and eudaimonic well-being concepts. In Handbook of Media Use and Well-Being; Reinecke, L., Oliver, M.B., Eds.; Routledge: New York, NY, USA, 2015; pp. 14-34, ISBN 1138886580.

9. Berridge, K.C.; Kringelbach, M.L. Building a neuroscience of pleasure and well-being. Psychol. Well. Being 2011, 1, 1-3. [CrossRef] 
10. Steger, M.F.; Shin, J.Y. Happiness and meaning in a technological age: A psychological approach. In The Good Life in a Technological Age; Brey, P., Briggle, A., Spence, E., Eds.; Routledge: New York, NY, USA, 2012; pp. 92-108, ISBN 9780415891264.

11. Huta, V.; Pelletier, L.; Baxter, D.; Thompson, A. How eudaimonic and hedonic motives relate to the well-being of close others. J. Posit. Psychol. 2012, 7, 399-404. [CrossRef]

12. Bergland, A.; Meaas, I.; Debesay, J.; Brovold, T.; Jacobsen, E.L.; Antypas, K. Associations of social networks with quality of life, health and physical functioning. Eur. J. Physiother. 2016, 18, 78-88. [CrossRef]

13. Hemmati, A.; Chung, K.S.K. Quality of life: A social network's perspective. Soc. Netw. Anal. Min. 2016, 6, 96. [CrossRef]

14. Helliwell, J.; Putnam, R. The social context of well-being. Philos. Trans. R. Soc. Lond. B Biol. Sci. 2004, 359, 1435-1446. [CrossRef]

15. Becchetti, L.; Pelloni, A.; Rossetti, F. Relational goods, sociability, and happiness. Kyklos 2008, 61, $343-363$. [CrossRef]

16. Bartolini, S.; Sarracino, F. Happy for how long? How social capital and economic growth relate to happiness over time. Ecol. Econ. 2014, 108, 242-256. [CrossRef]

17. Bruni, L.; Stanca, L. Watching alone: Relational goods, television and happiness. J. Econ. Behav. Organ. 2008, 65, 506-528. [CrossRef]

18. Colombo, E.; Rotondi, V.; Stanca, L. Macroeconomic conditions and well-being: Do social interactions matter? Appl. Econ. 2018, 50, 3029-3038. [CrossRef]

19. Ranis, G.; Stewart, F.; Samman, E. Human development: Beyond the human development index. J. Hum. Dev. Capabil. 2006, 7, 323-358. [CrossRef]

20. Cooperrider, D.; Fry, R. Mirror flourishing and the positive psychology of sustainability. J. Corp. Citizenship 2012, 46, 3-12. [CrossRef]

21. Schaefer, K.; Corner, P.D.; Kearins, K. Social, environmental and sustainable entrepreneurship research: What is needed for sustainability-as-flourishing? Organ. Environ. 2015, 28, 394-413. [CrossRef]

22. Easton, S. Electing the electorate: The problem of prisoner disenfranchisement. Mod. Law Rev. 2006, 69, 443-452. [CrossRef]

23. Griessler, E.; Littig, B. Social sustainability: A catchword between political pragmatism and social theory. Int. J. Sustain. Dev. 2005, 8, 65-79. [CrossRef]

24. Di Fabio, A. The Psychology of sustainability and sustainable development for well-being in organizations. Front. Psychol. 2017, 8, 1534. [CrossRef]

25. Deci, E.L.; Ryan, R.M. The 'what' and 'why' of goal pursuits: Human needs and the self-determination of behavior. Psychol. Inq. 2000, 11, 227-268. [CrossRef]

26. Ryan, R.M. Psychological needs and the facilitation of integrative processes. J. Pers. 1995, 63, $397-427$. [CrossRef]

27. Csikszentmihalyi, M. Beyond Boredom and Anxiety; Jossey-Bass: San Francisco, CA, USA, 1975; ISBN 109780787951405.

28. Deci, E.L. Intrinsic Motivation; Plenum: New York, NY, USA, 1975; ISBN 0306344017, 9780306344015.

29. Baumeister, R.; Leary, M.R. The need to belong: Desire for interpersonal attachments as a fundamental human motivation. Psychol. Bull. 1995, 117, 497-529. [CrossRef]

30. Deci, E.L.; Ryan, R.M. Intrinsic Motivation and Self-Determination in Human Behavior; Plenum: New York, NY, USA, 1985; ISBN 109780306420221.

31. Reis, H.T.; Franks, P. The role of intimacy and social support in health outcomes: Two processes or one? Pers. Relationsh. 1994, 1, 185-197. [CrossRef]

32. Ryan, R.M.; Deci, E.L. Self-determination theory and the facilitation of intrinsic motivation, social development, and well-being. Am. Psychol. 2000, 55, 68-78. [CrossRef]

33. Reis, H.T.; Sheldon, K.M.; Gable, S.L.; Roscoe, J.; Ryan, R.M. Daily well-being: The role of autonomy, competence, and relatedness. Pers. Soc. Psychol. B 2000, 26, 419-435. [CrossRef]

34. Sheldon, K.M.; Reis, H.T.; Ryan, R. What makes for a good day? Competence and autonomy in the day and in the person. Pers. Soc. Psychol. Bull. 1996, 22, 1270-1279. [CrossRef]

35. Deci, E.L.; Ryan, R.M. Motivation, personality, and development within embedded social contexts: An overview of self-determination theory. In The Oxford Handbook of Human Motivation; Ryan, R.M., Ed.; Oxford University Press: Oxford, UK, 2012; pp. 85-107, ISBN 100199366233. 
36. Blais, M.R.; Sabourin, S.; Boucher, C.; Vallerand, R.J. Toward a motivational model of couple happiness. J. Pers. Soc. Psychol. 1990, 59, 1021-1031. [CrossRef]

37. Levesque, C.; Zuehlke, A.N.; Stanek, L.R.; Ryan, R.M. Autonomy and competence in German and American university students: A comparative study based on self-determination theory. J. Educ. Psychol. 2004, 96, 68-84. [CrossRef]

38. Ryan, R.M.; Deci, E.L. A Self-Determination Theory perspective on social, institutional, cultural, and economic supports for autonomy and their importance for well-being. In Human Autonomy in Cross-Cultural Context. Cross-Cultural Advancements in Positive Psychology; Chirkov, V., Ryan, R., Sheldon, K., Eds.; Springer: Dordrecht, The Netherlands, 2011; pp. 45-64, ISBN 978-90-481-9667-8.

39. Demir, M.; Özdemir, M. Friendship, need satisfaction and happiness. J. Happiness Stud. 2010, 11, $243-259$. [CrossRef]

40. Pavey, L.; Greitemeyer, T.; Sparks, P. Highlighting relatedness promotes prosocial motives and behavior. Pers. Soc. Psychol. Bull. 2011, 37, 905-917. [CrossRef]

41. Perreault, D.; Mask, L.; Morgana, M.; Blanchard, C.M. Internalizing emotions: Self-determination as an antecedent of emotional intelligence. Personal. Individ. Differ. 2014, 64, 1-6. [CrossRef]

42. Di Fabio, A.; Palazzeschi, L.; Bucci, O.; Guazzini, A.; Burgassi, C.; Pesce, E. Personality traits and positive resources of workers for sustainable development: Is emotional intelligence a mediator for optimism and hope? Sustainability 2018, 10, 3422. [CrossRef]

43. Mayer, J.D.; Salovey, P.; Caruso, D.R. MSCEIT User's Manual; Multi-Health Systems: Toronto, ON, Canada, 2002.

44. Di Fabio, A.; Saklofske, D.H. The contributions of personality and emotional intelligence to resiliency. Personal. Individ. Differ. 2018, 123, 140-144. [CrossRef]

45. Charbonneau, D.; Nicol, A. Emotional intelligence and prosocial behaviors in adolescents. Psychol. Rep. 2002, 90, 361-370. [CrossRef]

46. Kaltwasser, L.; Hildebrandt, A.; Wilhelm, O.; Sommer, W. On the relationship of emotional abilities and prosocial behavior. Evo. Hum. Behav. 2017, 38, 298-308. [CrossRef]

47. Emery, A.A.; Heath, N.L.; Mills, D.J. Basic psychological need satisfaction, emotion dysregulation, and non-suicidal self-injury engagement in young adults: An application of self-determination theory. J. Youth Adolesc. 2016, 45, 612-623. [CrossRef]

48. Kubiak, T.; Wiedig-Allison, M.; Zgoriecki, S.; Weber, H. Habitual goals and strategies in anger regulation: Psychometric evaluation of the anger-related reactions and goal inventory (ARGI). J. Individ. Differ. 2011, 32, 1-13. [CrossRef]

49. Wang, Y.; Kong, F.; Kong, X.; Zhao, Y.; Lin, D.; Liu, J. Unsatisfied relatedness, not competence or autonomy, increases trait anger through the right amygdala. Cogn. Affect. Behav. Neurosci. 2017, 17, 932-938. [CrossRef]

50. Costa, S.; Ingoglia, S.; Inguglia, C.; Liga, F.; Lo Coco, A.; Larcan, R. Psychometric Evaluation of the Basic Psychological Need Satisfaction and Frustration Scale (BPNSFS) in Italy. Meas. Eval. Couns. Dev. 2017, 51, 193-206. [CrossRef]

51. Schutte, N.S.; Malouff, J.M.; Hall, L.E.; Haggerty, D.J.; Cooper, J.T.; Golden, C.J.; Dornheim, L. Development and validation of a measure of emotional intelligence. Personal. Individ. Differ. 1998, 25, 167-177. [CrossRef]

52. Di Fabio, A.; Giannini, M.; Palazzeschi, I. Intelligenza emotiva: Proprietà psicometriche della emotional intelligence scale (EIS). Couns. G Ital. Ric. Appl. 2008, 1, 61-71.

53. Petrides, K.V.; Furnham, A. On the dimensional structure of emotional intelligence. Personal. Individ. Differ. 2000, 29, 313-320. [CrossRef]

54. Jowell, R.; The Central Co-ordinating Team. European Social Survey 2002/2003: Technical Report; Centre for Comparative Social Surveys, City University: London, UK, 2003.

55. Huppert, F.A.; Marks, N.; Clark, A.; Siegrist, J.; Stutzer, A.; VittersØ, J.; Wahrendorf, M. Measuring Well-being Across Europe: Description of the ESS Well-being Module and Preliminary Findings. Soc. Ind. Res. 2009, 91, 301-315. [CrossRef]

56. Hayes, A.F. Introduction to Mediation, Moderation, and Conditional Process Analysis: A Regression-Based Approach; The Guilford Press: New York, NY, USA, 2013; ISBN 9781462534654.

57. Hayes, A.F. PROCESS: A Versatile Computational Tool for Observed Variable Mediation, Moderation, and Conditional Process Modeling. White Paper. 2012. Available online: http://www.afhayes.com/public/ process2012.pdf (accessed on 28 October 2018). 
58. Little, T.D.; Rhemtulla, M.; Gibson, K.; Schoemann, A.M. Why the items versus parcels controversy needn't be one. Psychol. Methods 2013, 18, 285-300. [CrossRef]

59. Molino, M.; Cortese, C.G.; Ghislieri, C. Unsustainable working conditions: The association of destructive leadership, use of technology, and workload with workaholism and exhaustion. Sustainability 2019, 11, 446. [CrossRef]

60. Little, T.D.; Cunningham, W.A.; Shahar, G.; Widaman, K.F. To parcel or not to parcel: Exploring the question, weighing the merits. Struct. Equ. Model. 2002, 9, 151-173. [CrossRef]

61. Preacher, K.J.; Hayes, A.F. Asymptotic and resampling strategies for assessing and comparing indirect effects in multiple mediator models. Behav. Res. Methods 2008, 40, 879-891. [CrossRef]

62. Podsakoff, P.M.; MacKenzie, S.B.; Lee, J.-Y.; Podsakoff, N.P. Common method biases in behavioral research: A critical review of the literature and recommended remedies. J. Appl. Psychol. 2003, 88, 879-903. [CrossRef]

63. Podsakoff, P.M.; MacKenzie, S.B.; Podsakoff, N.P. Sources of method bias in social science research and recommendations on how to control it. Annu. Rev. Psychol. 2012, 63, 539-569. [CrossRef]

64. Hair, J.F.; Black, W.C.; Babin, B.J.; Anderson, R.E. Multivariate Data Analysis: A Global Perspective, 7th ed.; Pearson Prentice Hall Publishing: Upper Saddle River, NJ, USA, 2010; ISBN 10 1-292-02190-X.

65. Fornell, C.; Larcker, D.F. Evaluating structural equation models with unobservable variables and measurement error. J. Mark. Res. 1981, 18, 39-50. [CrossRef]

66. Vandercammen, L.; Hofmans, J.; Theuns, P. Relating specific emotions to intrinsic motivation: On the moderating role of positive and negative emotion differentiation. PLoS ONE 2014, 9, e115396. [CrossRef]

67. Watson, M.; Kleinert, J. The relationship between coaches' emotional intelligence and basic need satisfaction in athletes. Sports Coach. Rev. 2018, in press. [CrossRef]

68. Di Fabio, A.; Kenny, M.E. Promoting well-being: The contribution of emotional intelligence. Front. Psychol. 2016, 7, 1182. [CrossRef]

69. Hofer, J.; Busch, H. Satisfying one's needs for competence and relatedness: Consequent domain-specific well-being depends on strength of implicit motives. Pers. Soc. Psychol. Bull. 2011, 37, 1147-1158. [CrossRef]

70. Eisenberg, N.; Losoya, S.; Spinrad, T. Affect and prosocial responding. In Handbook of Affective Sciences; Davidson, R., Scherer, K., Goldsmith, H., Eds.; Oxford University Press: Oxford, UK, 2003; pp. 85-107, ISBN 9780195377002.

71. Corral-Verdugo, V. A structural model of pro-environmental competency. Environ. Behav. 2002, 34, 531-549. [CrossRef]

72. Corral-Verdugo, V.; Bonnes, M.; Tapia, C.; Fraijo, B.; Frı'as, M.; Carrus, G. Correlates of pro-sustainability orientation: The affinity towards diversity. J. Environ. Psychol. 2009, 29, 34-43. [CrossRef]

73. Baltar, F.; Brunet, I. Social research 2.0: Virtual snowball sampling method using Facebook. Internet Res. 2012, 22, 57-74. [CrossRef]

74. Chernick, M.R. Bootstrap Methods: A Guide for Practitioners and Researchers, 2nd ed.; Wiley: Hoboken, NJ, USA, 2007; ISBN 9780471756217.

75. Spector, P.E. Method variance in organizational research: Truth or urban legend. Organ. Res. Methods 2006, 9, 221-232. [CrossRef]

76. Arfara, C.; Samanta, I. The impact of emotional intelligence on improving team-working: The case of Public Sector. Proced. Soc. Behv. 2016, 230, 167-175. [CrossRef]

77. Ojala, M. Emotional Awareness: On the importance of including emotional aspects in education for sustainable development (ESD). J. Educ. Sustain. Dev. 2013, 7, 167-182. [CrossRef]

(C) 2019 by the authors. Licensee MDPI, Basel, Switzerland. This article is an open access article distributed under the terms and conditions of the Creative Commons Attribution (CC BY) license (http://creativecommons.org/licenses/by/4.0/). 